\title{
Specific Autocatalysis in Diastereoisomeric Replicators
}

Eleftherios Kassianidis, Russell J. Pearson, Douglas Philp*

Centre for Biomolecular Sciences, School of Chemistry, University of St Andrews, North Haugh, St Andrews, Fife KY16 9ST, United Kingdom

d.philp@st-andrews.ac.uk

\section{SUPPLEMENTARY} INFORMATION 


\section{Spectroscopic Data for Selected Compounds}

\section{3-(2,5-Dioxo-2,5-dihydro-pyrrol-1-yl)- $N$-methyl- $N$-phenyl propionamide 1}

Mp: 124.2-124.8 ${ }^{\circ} \mathrm{C} .{ }^{1} \mathrm{H}$ NMR $\left(\mathrm{CDCl}_{3}, 300 \mathrm{MHz}\right): \delta_{\mathrm{H}} 7.45-7.29(\mathrm{~m}, 3 \mathrm{H}), 7.23-7.15(\mathrm{~m}, 2 \mathrm{H}), 6.63$ (s, $2 \mathrm{H}), 3.75(\mathrm{t}, 2 \mathrm{H}, J=7.4 \mathrm{~Hz}), 3.22(\mathrm{~s}, 3 \mathrm{H}), 2.36(\mathrm{t}, 2 \mathrm{H}, J=7.4 \mathrm{~Hz}) .{ }^{13} \mathrm{C} \mathrm{NMR}\left(\mathrm{CDCl}_{3}, 75 \mathrm{MHz}\right): \delta_{\mathrm{C}}$ $170.8,170.2$, 143.8, 134.5, 130.3, 128.4, 127.6, 37.5, 34.5, 32.8. IR (KBr): 3448, 2968, 2362, 1964, 1892, 1810, 1777, 1695, 1642, 1584, 1490, 1450, 1401, 1329, 1296, 1267, 1243, 1137, 1118, $1031 \mathrm{~cm}^{-1}$. MS (EI+) $m / z 258$ ([M] $\left.]^{+}, 50 \%\right), 152$ (15), 107 (100). HRMS (EI+) calculated for $\mathrm{C}_{14} \mathrm{H}_{14} \mathrm{~N}_{2} \mathrm{O}_{3}[\mathrm{M}]^{+}$ 258.10044, found 258.10120. Calculated for $\mathrm{C}_{14} \mathrm{H}_{14} \mathrm{~N}_{2} \mathrm{O}_{3}$ : C, 65.11; H, 5.46; N, 10.85. Found: C, 64.96; H, 5.38; N, 10.78 .

\section{Furan-2-yl-acetic acid 2}

Mp: 66.1-66.6 ${ }^{\circ} \mathrm{C} .{ }^{1} \mathrm{H}$ NMR $\left(\mathrm{CDCl}_{3}, 300 \mathrm{MHz}\right): \delta_{\mathrm{H}} 8.58(\mathrm{br}, 1 \mathrm{H}), 7.37(\mathrm{dd}, 1 \mathrm{H}, J=0.8$ and $1.8 \mathrm{~Hz})$, $6.35(\mathrm{dd}, 1 \mathrm{H}, J=1.9$ and $3.2 \mathrm{~Hz}), 6.25(\mathrm{dd}, 1 \mathrm{H}, J=0.7$ and $3.2 \mathrm{~Hz}), 3.73(\mathrm{~s}, 2 \mathrm{H}) .{ }^{13} \mathrm{C} \mathrm{NMR}\left(\mathrm{CDCl}_{3}, 75\right.$ $\mathrm{MHz}): \delta_{\mathrm{C}} 175.5,146.9,142.3,110.5,108.4,33.7$. IR (KBr): 3135, 2933, 1697, 1611, 1504, 1423, 1389, $1245,1168,1077,1009 \mathrm{~cm}^{-1}$. MS (EI+) $\mathrm{m} / z\left([\mathrm{M}]^{+}, 100 \%\right)$. HRMS (EI+) calculated for $\mathrm{C}_{6} \mathrm{H}_{6} \mathrm{O}_{3}[\mathrm{M}]^{+}$ 126.031694 , found 126.031518 .

\section{3-(2,5-Dioxo-2,5-dihydro-pyrrol-1-yl)- $N$-(6-methyl-pyridin-2-yl) propionamide 3}

Mp: 154.7-156.0 ${ }^{\circ} \mathrm{C} .{ }^{1} \mathrm{H} \mathrm{NMR}\left(\mathrm{CDCl}_{3}, 300 \mathrm{MHz}\right): \delta_{\mathrm{H}} 8.18(\mathrm{br}, 1 \mathrm{H}), 7.70(\mathrm{~d}, 1 \mathrm{H}, J=7.8 \mathrm{~Hz}), 7.55(\mathrm{t}$, $1 \mathrm{H}, J=7.8 \mathrm{~Hz}), 6.86(\mathrm{~d}, 1 \mathrm{H}, J=7.7 \mathrm{~Hz}), 6.76(\mathrm{~s}, 2 \mathrm{H}), 3.85(\mathrm{t}, 2 \mathrm{H}, J=7.0 \mathrm{~Hz}), 2.60(\mathrm{t}, 2 \mathrm{H}, J=7.0 \mathrm{~Hz})$, $2.31(\mathrm{~s}, 3 \mathrm{H}) .{ }^{13} \mathrm{C} \mathrm{NMR}\left(\mathrm{CDCl}_{3}, 75 \mathrm{MHz}\right): \delta_{\mathrm{C}} 170.8,165.0,157.0,150.7,139.2,134.6,119.8,111.4$, 35.8, 34.2, 24.2. IR (KBr): 3315, 3084, 1763, 1700, 1604, 1546, 1455, 1421, 1402, 1373, 1296, 1229, $1200,1142 \mathrm{~cm}^{-1}$. MS (EI+) $\mathrm{m} / z 259\left([\mathrm{M}]^{+}, 25 \%\right), 108(100)$. HRMS (EI+) calculated for $\mathrm{C}_{13} \mathrm{H}_{13} \mathrm{~N}_{3} \mathrm{O}_{3}$ $[\mathrm{M}]^{+}$259.09569, found 259.09569.

\section{\{4-[2-(6-Methyl-pyridin-2-ylcarbamoyl)-ethyl]-3,5-dioxo-10-oxa-4-aza-tricyclo [5.2.1.0 $\left.{ }^{2,6}\right]$ dec-8-en-} 1-yl acetic acid endo-5

Mp: $180.4-180.9{ }^{\circ} \mathrm{C} .{ }^{1} \mathrm{H}$ NMR (DMSO- $\left.d_{6}, 500 \mathrm{MHz}\right): \delta_{\mathrm{H}} 10.34\left(\mathrm{br}, 1 \mathrm{H}_{\text {endo }}\right), 7.84(\mathrm{~d}, 1 \mathrm{H}, J=7.6 \mathrm{~Hz})$, $7.65(\mathrm{t}, 1 \mathrm{H}, J=7.6 \mathrm{~Hz}), 6.95(\mathrm{~d}, 1 \mathrm{H}, J=7.5 \mathrm{~Hz}), 6.36(\mathrm{~d}, 1 \mathrm{H}, J=5.7 \mathrm{~Hz}), 6.31(\mathrm{~d}, 1 \mathrm{H}, J=5.6 \mathrm{~Hz}), 5.24$ $(\mathrm{dd}, 1 \mathrm{H}, J=1.2$ and $5.5 \mathrm{~Hz}), 3.53-3.48(\mathrm{~m}, 4 \mathrm{H}), 3.08-3.05(\mathrm{~d}, 1 \mathrm{H}, J=15.5 \mathrm{~Hz}), 2.98-2.95(\mathrm{~d}, 1 \mathrm{H}, J=$ $15.2 \mathrm{~Hz}), 2.54(\mathrm{t}, 2 \mathrm{H}, J=7.3 \mathrm{~Hz}), 2.40(\mathrm{~s}, 3 \mathrm{H}) .{ }^{13} \mathrm{C}$ NMR (DMSO- $\left.d_{6}, 125 \mathrm{MHz}\right): \delta_{\mathrm{C}} 174.6,174.4,170.0$, $169.1,156.3,138.3,136.4,134.5,133.5,110.3$, 87.6, 87.0, 78.5, 39.8, 37.0, 33.9, 33.5, IR (KBr): 3459, 3276, 3122, 3084, 2949, 2372, 1772, 1700, 1618, 1575, 1455, 197, 1320, $\mathrm{cm}^{-1}$. MS (ES-) m/z $384([\mathrm{M}-$ $\left.\mathrm{H}]^{+}, 100 \%\right)$. HRMS (ES-) calculated for $\mathrm{C}_{19} \mathrm{H}_{18} \mathrm{~N}_{3} \mathrm{O}_{6}[\mathrm{M}-\mathrm{H}]^{+} 384.1196$, found 384.1186. 


\section{1-yl\} acetic acid exo-5}

Mp: 194.4-194.9 ${ }^{\circ} \mathrm{C} .{ }^{1} \mathrm{H}$ NMR (DMSO- $d_{6}, 500 \mathrm{MHz}$ ): $\delta_{\mathrm{H}} 10.39$ (br, $\left.1 \mathrm{H}\right), 7.84(\mathrm{~d}, 1 \mathrm{H}, J=7.6 \mathrm{~Hz}$ ), 7.63 $(\mathrm{t}, 1 \mathrm{H}, J=7.7 \mathrm{~Hz}), 6.95(\mathrm{~d}, 1 \mathrm{H}, J=7.5 \mathrm{~Hz}), 6.56(\mathrm{~d}, 1 \mathrm{H}, J=1.3 \mathrm{~Hz}), 6.55(\mathrm{~d}, 1 \mathrm{H}, J=5.7 \mathrm{~Hz}), 5.07(\mathrm{~d}$, $1 \mathrm{H}, J=1.4 \mathrm{~Hz}), 3.65(\mathrm{dt}, 2 \mathrm{H}, J=3.4$ and $9.0 \mathrm{~Hz}), 3.53-3.08(\mathrm{~d}, 1 \mathrm{H}, J=6.5 \mathrm{~Hz}), 3.02(\mathrm{~d}, 1 \mathrm{H}, J=6.5$ $\mathrm{Hz}), 2.95(\mathrm{~d}, 1 \mathrm{H}, J=16.9 \mathrm{~Hz}), 2.91(\mathrm{~d}, 1 \mathrm{H}, J=16.9 \mathrm{~Hz}), 2.64-2.60(\mathrm{dt}, 2 \mathrm{H}, J=2.6$ and $7.2 \mathrm{~Hz}), 2.40(\mathrm{~s}$, $3 \mathrm{H}) .{ }^{13} \mathrm{C}$ NMR (DMSO- $d_{6}, 125 \mathrm{MHz}$ ): $\delta_{\mathrm{C}} 175.8,174.6,170.6,169.1,156.3,151.2,139.0,138.2,136.3$, 118.4, 110.5, 79.7, 49.8, 48.4, 47.4, 34.4, 34.2, 33.8, 23.4. IR (KBr): 3459, 3276, 3122, 3084, 2949, 2372, 1772, 1700, 1618, 1575, 1455, 1397, 1320, $1157 \mathrm{~cm}^{-1}$. MS (ES-) $\mathrm{m} / z 384\left([\mathrm{M}-\mathrm{H}]^{+}, 100 \%\right)$. HRMS (ES-) calculated for $\mathrm{C}_{19} \mathrm{H}_{18} \mathrm{~N}_{3} \mathrm{O}_{6}[\mathrm{M}-\mathrm{H}]^{+}$384.1196, found 384.1186.

\section{nOe Data for endo-5 and exo-5}

${ }^{1} \mathrm{H}$ NMR spectra were acquired at $25^{\circ} \mathrm{C}$ in $\mathrm{CDCl}_{3}$ on a Bruker Avance 500 spectrometer $\left({ }^{1} \mathrm{H}=500\right.$ MHz) equipped with a TXI triple resonance probe $\left({ }^{1} \mathrm{H} /{ }^{13} \mathrm{C} /{ }^{15} \mathrm{~N}\right)$. Nuclear Overhauser Effect (nOe) data were obtained using the 1D GOESY pulse sequence. Observed nOes are shown as red double headed arrows on the molecular structures below. Data were acquired at two concentrations $-2.5 \mathrm{mM}$ and $10.0 \mathrm{mM}$ - and each experiment was performed in triplicate. Other intramolecular nOes were observed, but have been omitted for clarity. No nOes were observed between endo-5 and $\boldsymbol{e x \boldsymbol { o } - 5}$. This result places an upper limit of $5 \%$ on the amount of the heterodimer present in solution at equilibrium.
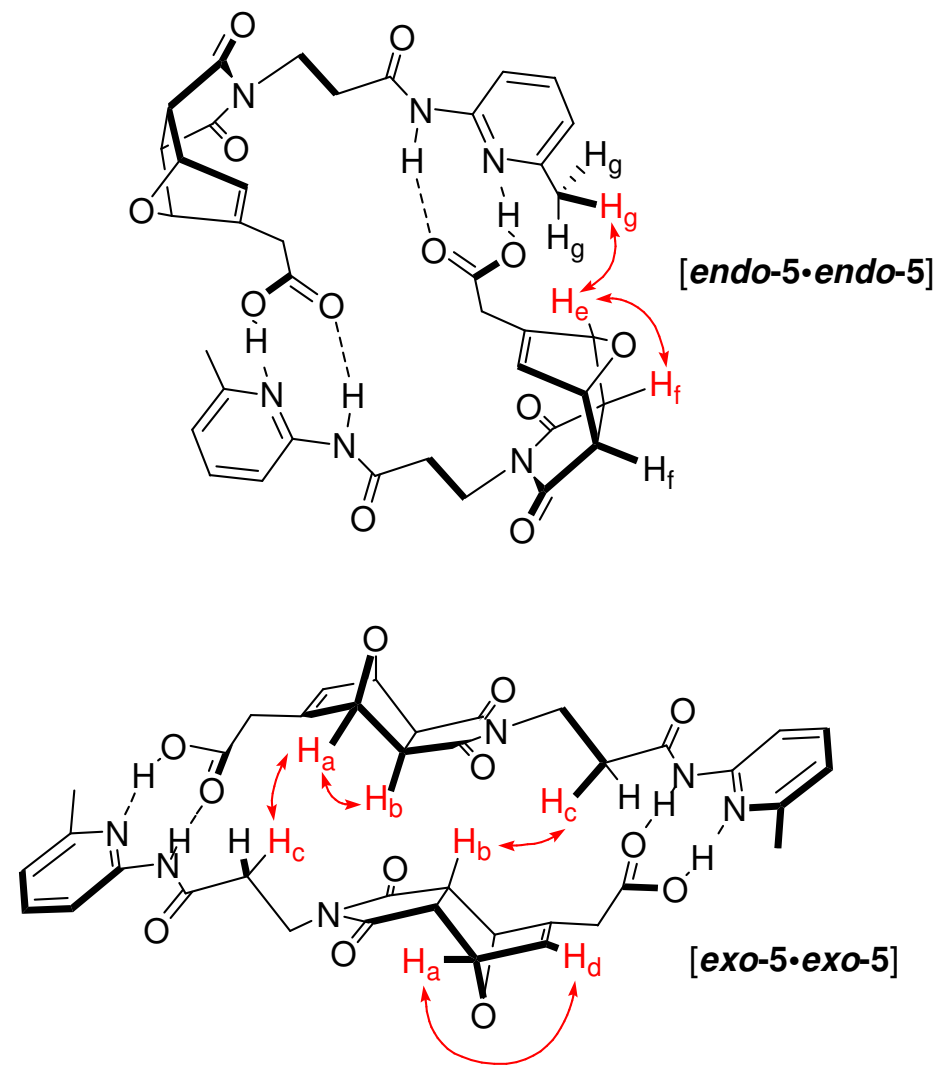


\section{Kinetic Simulation and Fitting}

Elucidation of esoteric mechanistic subtleties of recognition-mediated processes revolves around construction of simulation models that faithfully reproduce experimental time-courses, thus maximising the level of precision in estimation of rate constant values of contributing reactive pathways.

Accurate depictions of the complex function of systems encompassing parallel operation of two antagonistic self-replicating units, comprise a plethora of interlinked rapid equilibria (see Figure S1):

\begin{tabular}{|c|c|c|c|c|c|c|}
\hline Bimolecular & \multicolumn{2}{|c|}{ Reactions } & \multicolumn{2}{|c|}{ Ternary complex reactions } & \multicolumn{2}{|c|}{ Complex associations } \\
\hline$A+B$ & $\rightleftarrows$ & T1 & {$[A \cdot B \cdot T 1]$} & $\rightleftarrows[\mathrm{T} 1 \cdot \mathrm{T} 1]$ & $A+B$ & $\rightarrow \quad[\mathrm{A} \cdot \mathrm{B}]$ \\
\hline \multirow[t]{2}{*}{$A+B$} & 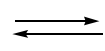 & T2 & {$[\mathrm{A} \cdot \mathrm{B} \cdot \mathrm{T} 2]$} & $\rightleftarrows[\mathrm{T} 2 \cdot \mathrm{T} 2]$ & $A+B+T 1$ & $\rightarrow[A \cdot B \cdot T 1]$ \\
\hline & & & {$[\mathrm{A} \cdot \mathrm{B} \cdot \mathrm{T} 1]$} & $\longrightarrow[\mathrm{T} 1 \cdot \mathrm{T} 2]$ & $A+B+T 2$ & {$[A \cdot B \cdot T 2]$} \\
\hline \multicolumn{2}{|c|}{ Product duplex } & sociations & {$[\mathrm{A} \cdot \mathrm{B} \cdot \mathrm{T} 2]$} & $\rightleftarrows[\mathrm{T} 2 \cdot \mathrm{T} 1]$ & $\mathrm{T} 1+\mathrm{A}$ & {$[\mathrm{T} 1 \cdot \mathrm{A}]$} \\
\hline$[\mathrm{T} 1 \cdot \mathrm{T} 1]$ & & $\mathrm{T} 1+\mathrm{T} 1$ & \multicolumn{2}{|c|}{ Binary complex reactions } & $\mathrm{T} 1+\mathrm{B}$ & $=[\mathrm{T} 1 \cdot \mathrm{B}]$ \\
\hline$[\mathrm{T} 2 \cdot \mathrm{T} 2]$ & & $\mathrm{T} 2+\mathrm{T} 2$ & {$[A \cdot B]$} & $\rightarrow \mathrm{T} 1$ & $\mathrm{~T} 2+\mathrm{A}$ & $\geq \quad[\mathrm{T} 2 \cdot \mathrm{A}]$ \\
\hline$[\mathrm{T} 1 \cdot \mathrm{T} 2]$ & $\rightleftarrows$ & $\mathrm{T} 1+\mathrm{T} 2$ & {$[\mathrm{~A} \cdot \mathrm{B}]$} & $\rightleftarrows \mathrm{T} 2$ & $\mathrm{~T} 2+\mathrm{B}$ & {$[\mathrm{T} 2 \cdot \mathrm{B}]$} \\
\hline \multicolumn{7}{|c|}{ Miscellaneous intra-complex reactions } \\
\hline$[A \cdot B]+B$ & $\rightleftarrows$ & $\mathrm{T} 1+\mathrm{B}$ & {$[A \cdot T 1]+B$} & $\rightleftarrows[\mathrm{T} 1 \cdot \mathrm{T} 1]$ & {$[A \cdot T 1]+B$} & $\rightarrow[\mathrm{T} 1 \cdot \mathrm{T} 2]$ \\
\hline$A+[A \cdot B]$ & - & $\mathrm{T} 1+\mathrm{A}$ & $\mathrm{A}+[\mathrm{T} 1 \cdot \mathrm{B}]$ & $\rightleftarrows[\mathrm{T} 1 \cdot \mathrm{T} 1]$ & $\mathrm{A}+[\mathrm{T} 1 \cdot \mathrm{B}]$ & $\rightleftarrows[\mathrm{T} 1 \cdot \mathrm{T} 2]$ \\
\hline$[A \cdot B]+B$ & & $\mathrm{~T} 2+\mathrm{B}$ & {$[A \cdot T 2]+B$} & $\rightleftarrows$ [T2・T2] & {$[A \cdot T 2]+B$} & $\rightarrow[\mathrm{T} 2 \cdot \mathrm{T} 1]$ \\
\hline$A+[A \cdot B]$ & $\rightleftarrows$ & $\mathrm{T} 2+\mathrm{A}$ & $\mathrm{A}+[\mathrm{T} 2 \cdot \mathrm{B}]$ & $\rightleftarrows$ [T2・T2] & $\mathrm{A}+[\mathrm{T} 2 \cdot \mathrm{B}]$ & $\rightleftarrows[\mathrm{T} 2 \cdot \mathrm{T} 1]$ \\
\hline
\end{tabular}

Figure S1 Successive equilibria and intermediates during self-replicative proliferation of templates $\mathrm{T} 1$ and $\mathrm{T} 2$.

Integration of the binary reactive complex pathway (for both endo-5 and exo-5) to our calculations constituted a significant aspect of our stratagem. It was anticipated that general production patterns of endo-5 and exo-5 would remain largely unaffected by the formation of binary complexes [2•3] (vide infra). Within the binary complex setting, correct alignment of reactive molecular orbitals in either an endo or exo orientation, requires the introduction of substantial strain into the noncovalently bound transition state structure $[\mathbf{2 \cdot 3}]^{\ddagger}$, entailing elevation of activation energy barriers and low reaction rates for production of endo-5 and $\boldsymbol{e x \boldsymbol { o } - 5}$. Strain is relieved by gradual elongation (in the post-transition state phase) and eventual destruction of hydrogen bonds (in the product ground state), liberating recognition termini of endo-5 and exo-5. Therefore, minute fractions of catalytically potent endo-5 and exo-5 are engendered via the binary complex channel

Despite the limited accelerating capability of the binary complex pathway, high distributions of $[\mathbf{A} \cdot \mathbf{B}]$ species at the initial stages of the process heavily impact initial rates. Oversight of such delicate effects leads to substantial errors in estimations of absolute rate constants.

Previous investigations within our group indicated that preactivation of substrates via complexation by templates (see Figure S1, miscellaneous intracomplex reactions) or complementary fragments, exerts negligible catalytic influence on rates of subsequent intermolecular reactions. Such phenomena occur at the bimolecular reaction rate and warrant no special consideration. Accordingly, the kinetic algorithm depicted in Figure S3 was constructed.

On the whole, we postulated that species endo-5 and exo-5 are engendered via coincident function of three channels: the bimolecular, non-templated channel, the binary reactive complex channel and the templated (ternary complex) channel (see Figure S3).

At the outset, approximations for rate constants $k_{1}, k_{2}, k_{3}$ and $k_{4}$ were a priori obtained via extrapolation from the prototypical bimolecular reaction between $\mathbf{1}$ and 2, utilising the simple model in Figure S2. 


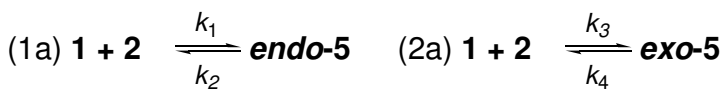

Figure S2 Kinetic model utilised in computations of magnitudes of rate constants $k_{1}-k_{4}$, characteristic of bimolecular unions between 1 and non-associating dienophile 2.

Optimal fit of theoretical (depicted as solid lines in Figure 2, main text) to experimental conversion $v s$. time curves was observed for rate constant values $\left(k_{1}, k_{2}, k_{3}\right.$ and $\left.k_{4}\right)$ of:

$$
\begin{array}{ll}
k_{1}=7.43( \pm 0.14) \times 10^{-5} \mathrm{M}^{-1} \mathrm{~s}^{-1} & k_{2}=1.75( \pm 0.18) \times 10^{-7} \mathrm{~s}^{-1} \\
k_{3}=4.58( \pm 0.12) \times 10^{-5} \mathrm{M}^{-1} \mathrm{~s}^{-1} & k_{4}=3.35( \pm 0.41) \times 10^{-7} \mathrm{~s}^{-1}
\end{array}
$$

The percentage of the mean absolute difference between experimental and theoretical concentrations with respect to the experimental concentrations $(R \%)$ was less than 1.0.

Unfortunately, identification of model reactions appropriate for emulating the kinetic traits of the binary reactive complex pathway presented insurmountable obstacles, necessitating determination of $k_{9}, k_{10}, k_{11}$ and $k_{12}$ by numerical methods. Therefore, magnitude estimates for rate constants $k_{1}, k_{2}, k_{3}$ and $k_{4}$ were incorporated into the comprehensive scheme displayed in Figure S3 (representative of the overall recognition-mediated process) as invariant, predefined parameters. Subsequent minimisation of input data forged theoretical curves (depicted as solid lines in Figure 2, main text) being in perfect

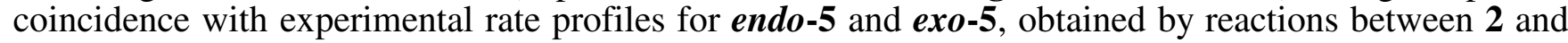
3.

Uncatalysed bimolecular reaction pathway
(1) $2+3 \underset{k_{2}}{\stackrel{k_{1}}{\rightleftharpoons}}$ endo-5

(2) $2+3 \stackrel{k_{3}}{\frac{k_{4}}{=}}$ exo-5

Productive complex associations

(3) $2+$ endo-5 $\stackrel{\mathrm{K}_{1}}{=}[2 \cdot$ endo-5]

(4) $2+$ exo-5 $\stackrel{\mathrm{K}_{2}}{\rightleftharpoons}[2 \cdot$ exo-5]

(5) $3+$ endo-5 $\stackrel{\mathrm{K}_{3}}{\rightleftharpoons}[3 \cdot$ endo-5]

(6) $3+$ exo-5 $\stackrel{\mathrm{K}_{4}}{\rightleftharpoons}[3 \cdot$ exo-5]

(7) $2+\left[3 \cdot\right.$ endo-5] $\stackrel{\mathrm{K}_{5}}{=}[2 \cdot 3 \cdot$ endo-5]

(8) $2+[3 \cdot e x o-5] \stackrel{\mathrm{K}_{6}}{\rightleftharpoons}[2 \cdot 3 \cdot$ exo-5]

(9) $3+\left[2 \cdot\right.$ endo-5] $\stackrel{\mathrm{K}_{7}}{\rightleftharpoons}[2 \cdot 3 \cdot$ endo-5]

(10) $3+[2 \cdot e x o-5] \stackrel{K_{8}}{\rightleftharpoons}[2 \cdot 3 \cdot e x o-5]$

(11) $2+3 \stackrel{\mathrm{K}_{9}}{\rightleftharpoons}[2 \cdot 3]$

Self-replication pathway

(12) $\left[2 \cdot 3 \cdot\right.$ endo-5] $\underset{k_{6}}{\stackrel{k_{5}}{\rightleftharpoons}}[$ endo-5•endo-5]

(13) $[2 \cdot 3 \cdot e x o-5] \underset{k_{8}}{\stackrel{k_{7}}{\rightleftharpoons}}[$ exo-5•exo-5]

Binary reactive complex pathway

(14) $[2 \cdot 3] \frac{k_{9}}{k_{10}}$ endo-5

(15) $[2 \cdot 3] \stackrel{k_{11}}{\frac{k_{12}}{2}}$ exo-5

Product duplex

dissociations

(16) $\left[\right.$ endo-5•endo-5] $\stackrel{\mathrm{K}_{10}}{\rightleftharpoons}$ endo-5 + endo-5
(17) $\left[\right.$ exo-5•exo-5] $\stackrel{\mathrm{K}_{11}}{\rightleftharpoons}$ exo-5 + exo-5

Figure S3 Comprehensive kinetic algorithm utilised in theoretical simulations of the manufacture of endo-5 and exo-5 via synchronous operation of three parallel reaction avenues. 
Our accuracy in determination of magnitudes of rate constants $k_{5}, k_{6}, k_{7}, k_{8}, k_{9}, k_{10}, k_{11}$ and $k_{12}$ was authenticated by $R \%$ values of 1.2. Optimal-fit values of the latter set of rate constants are shown below:

$$
\begin{array}{ll}
k_{5}=4.12( \pm 0.06) \times 10^{-5} \mathrm{~s}^{-1} & k_{6}=3.36( \pm 1.33) \times 10^{-7} \mathrm{~s}^{-1} \\
k_{7}=4.99( \pm 0.05) \times 10^{-5} \mathrm{~s}^{-1} & k_{8}=9.94( \pm 1.92) \times 10^{-7} \mathrm{~s}^{-1} \\
k_{9}=5.24( \pm 0.04) \times 10^{-6} \mathrm{~s}^{-1} & k_{10}=3.95( \pm 1.05) \times 10^{-7} \mathrm{~s}^{-1} \\
k_{11}=4.47( \pm 0.03) \times 10^{-6} \mathrm{~s}^{-1} & k_{12}=8.76( \pm 1.58) \times 10^{-7} \mathrm{~s}^{-1}
\end{array}
$$

Stability estimates for complexes [2•endo-5] $\left(\mathrm{K}_{1}\right)$, [2•exo-5] $\left(\mathrm{K}_{2}\right),\left[\mathbf{3} \bullet\right.$ endo-5] $\left(\mathrm{K}_{3}\right)$, [3•exo-5] $\left(\mathrm{K}_{4}\right)$ and $[2 \cdot 3]\left(\mathrm{K}_{9}\right)$ were obtained by analogy to interactions between the pairs of non-reactive model compounds shown in Scheme S1. The association constant between maleimide $\mathbf{6}$ and 3-methyl- $N$-(6-methyl-pyridin2-yl)-butyramide 7 was determined by titration, utilising $500 \mathrm{MHz}{ }^{1} \mathrm{H} \mathrm{NMR}$ spectroscopy at $35^{\circ} \mathrm{C}$ in $\mathrm{CDCl}_{3}$.

(a)

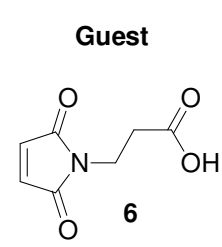

(b)

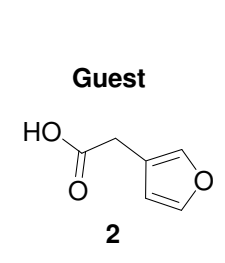

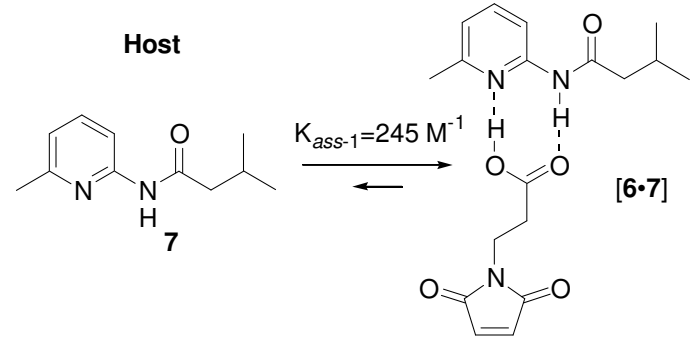

Host

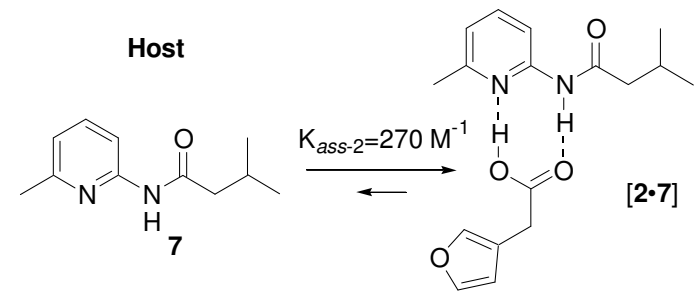

Scheme S1 Estimation of association constants $\mathrm{K}_{1}-\mathrm{K}_{9}$ by analogy to interactions between model compounds (a) 6 and 7 and (b) 2 and 7.

The concentration of guest $\mathbf{6}$ was varied between 0 and $70.0 \mathrm{mM}$ whilst that of the host 7 was maintained at $10 \mathrm{mM}$. The observed, complexation-induced change in chemical shift of the resonances arising from the proton in the 4-position of the pyridine ring in compound $\mathbf{7}$ was monitored as the concentration of guest was varied. Fitting of experimental data to the appropriate binding isotherm afforded $\mathrm{K}_{\text {ass-1 }}=245 \mathrm{M}^{-1}$. Similarly, employing 2 as the guest yielded $\mathrm{K}_{\text {ass }-2}=270 \mathrm{M}^{-1}$. An average value of $\mathrm{K}_{a s s}=\mathrm{K}_{1}=\mathrm{K}_{2}=\mathrm{K}_{3}=\mathrm{K}_{4}=\mathrm{K}_{9}=250 \mathrm{M}^{-1}$ was therefore used. Additionally, given that alkyl spacer units embedded in templates endo-5 and exo-5 limit steric and electronic interference between amidopicoline and carboxylic acid moieties (absence of positive or negative cooperativity) we assumed:

$$
\mathrm{K}_{\mathrm{ass}}=\mathrm{K}_{1}=\mathrm{K}_{2}=\mathrm{K}_{3}=\mathrm{K}_{4}=\mathrm{K}_{5}=\mathrm{K}_{6}=\mathrm{K}_{7}=\mathrm{K}_{8}=\mathrm{K}_{9}=250 \mathrm{M}^{-1}
$$

The limited solubility of cycloadducts endo-5 and exo-5 in $\mathrm{CDCl}_{3}$ at $35{ }^{\circ} \mathrm{C}$, proscribed accurate measurement of respective dimerisation constants $1 / \mathrm{K}_{10}$ and $1 / \mathrm{K}_{11}$ by ${ }^{1} \mathrm{H}$ NMR titration. Taking account of the classical chelate effect, dictating additivity of non-covalent interaction energies, initial assumptions about the extent of self-recognition of endo-5 and exo-5, logically comprised dimerisation

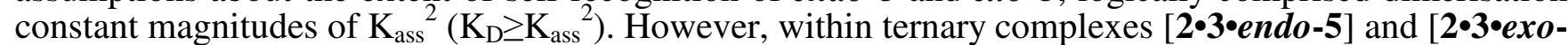
5], progression from planar transition states to pyramidal fused tricyclic cycloadducts, induces steric 
congestion in the middle of newly generated centrosymmetric aggregates [endo-5•endo-5] and [exo5•exo-5]. Specifically, steric repulsion between the central nuclei, encourages disconnection of cyclic dimers, decreasing the magnitude of $K_{D}$. Reasonable values of $1 / \mathrm{K}_{10}=260 \mathrm{M}^{-1}$ and $1 / \mathrm{K}_{11}=280 \mathrm{M}^{-1}$ were accommodated by our kinetic model in Figure S3, providing excellent correlation between simulation and experimental results (vide supra).

It is notable that the sensitivity of $R \%$ to variation of experimentally measured values for $\mathrm{K}_{\mathrm{ass}}\left(\mathrm{K}_{\mathrm{ass}}=\right.$ $\left.250 \mathrm{M}^{-1}\right)$ and calculated values for $1 / \mathrm{K}_{10}$ and $1 / \mathrm{K}_{11}\left(1 / \mathrm{K}_{10}=260 \mathrm{M}^{-1}, 1 / \mathrm{K}_{11}=250 \mathrm{M}^{-1}\right)$ was extraordinary: Small deviations, in the vicinity of $\pm 10 \%$, furnished uniformly poor fits $(R \%>2.5)$ for both the endo-5 and exo-5 datasets.

Resultant kinetic and thermodynamic effective molarities (denoted as $k \mathrm{EM}$ and $t \mathrm{EM}$, respectively) for the self-propagation of endo-5 and exo-5 were via application of equations (18) - (25):

$$
\begin{gathered}
k \mathrm{EM}_{\mathrm{SR}}(\text { endo-5 })=k_{5} / k_{1}=554 \mathrm{mM} \\
t \mathrm{EM}_{\mathrm{SR}}(\boldsymbol{e} \text { endo-5 })=k_{2} \times k_{5} / k_{1} \times k_{6}=289 \mathrm{mM} \\
k \mathrm{EM}_{\mathrm{SR}}(\boldsymbol{e x \boldsymbol { o } - 5})=k_{7} / k_{3}=1.1 \mathrm{M}(20) \\
t \mathrm{EM}_{\mathrm{SR}}(\boldsymbol{e x \boldsymbol { o } - 5})=k_{4} \times k_{7} / k_{3} \times k_{8}=367 \mathrm{mM}
\end{gathered}
$$

Whereas for the binary complex pathway:

$$
\begin{gathered}
k \mathrm{EM}_{\mathrm{BC}}(\text { endo-5 })=k_{9} / k_{1}=70 \mathrm{mM} \\
t \mathrm{EM}_{\mathrm{BC}}(\text { endo-5 })=k_{2} \times k_{9} / k_{1} \times k_{10}=31 \mathrm{mM} \\
k \mathrm{EM}_{\mathrm{BC}}(\boldsymbol{e x \boldsymbol { o } - 5})=k_{11} / k_{3}=96 \mathrm{mM} \\
t \mathrm{EM}_{\mathrm{BC}}(\text { exo-5 })=k_{4} \times k_{11} / k_{3} \times k_{12}=37 \mathrm{mM}
\end{gathered}
$$

Table S1 Computed kinetic and thermodynamic effective molarity values associated with manufacture of endo-5 and exo-5 via function of the self-replicative and the binary reactive complex pathways at $35^{\circ} \mathrm{C}$.

\begin{tabular}{ccccc}
\hline Pathway $\left(35^{\circ} \mathrm{C}\right)$ & $\begin{array}{c}k \mathrm{EM}(\text { endo-5 }) \\
{[\mathrm{mM}]}\end{array}$ & $\begin{array}{c}t \mathrm{EM}(\text { endo-5 }) \\
{[\mathrm{mM}]}\end{array}$ & $\begin{array}{c}k \mathrm{EM}(\text { exo-5 }) \\
{[\mathrm{mM}]}\end{array}$ & $\begin{array}{c}t \mathrm{EM}(\text { exo-5 }) \\
{[\mathrm{mM}]}\end{array}$ \\
\hline Self-replication & 554 & 289 & 1100 & 367 \\
Binary reactive complex & 70 & 31 & 96 & 37 \\
\hline
\end{tabular}

